\title{
The Southern Hemisphere semiannual oscillation and circulation variability during the Mid-Holocene
}

\author{
D. Ackerley and J. A. Renwick \\ National Institute of Water and Atmospheric Research Ltd, Private Bag 14901, Kilbirnie, Wellington, New Zealand \\ Received: 9 February 2010 - Published in Clim. Past Discuss.: 22 February 2010 \\ Revised: 21 June 2010 - Accepted: 22 June 2010 - Published: 5 July 2010
}

Abstract. The Paleoclimate Modelling Intercomparison Project (PMIP) was undertaken to assess the climatic effects of the presence of large ice-sheets and changes in the Earth's orbital parameters in fully coupled Atmosphere-Ocean General Circulation Models (AOGCMs). Much of the previous literature has focussed on the tropics and the Northern Hemisphere during the last glacial maximum and Mid-Holocene whereas this study focuses only on the Southern Hemisphere. This study addresses the representation of the Semiannual Oscillation (SAO) in the PMIP2 models and how it may have changed during the Mid-Holocene. The output from the five models suggest a weakening of the (austral) autumn circumpolar trough (CPT) and (in all but one model) a strengthening of the spring CPT. The effects of changing the orbital parameters are to cause warming and drying during spring over New Zealand and a cooling and moistening during autumn. The amount of spring warming/drying and autumn cooling/moistening is variable between the models and depends on the climatological locations of surface pressure anomalies associated with changes in the SAO. This study also undertakes an Empirical Orthogonal Function (EOF) analysis of the leading modes of atmospheric variability during the control and Mid-Holocene phases for each model. Despite the seasonal changes, the overall month by month and interannual variability was simulated to have changed little from the Mid-Holocene to present.

\section{Correspondence to: D. Ackerley} (d.ackerley@niwa.co.nz)

\section{Introduction}

The use of paleoclimate data and model simulations help to inform us of low-frequency climate variability on time scales longer than resolved in the instrumental record. Paleoclimate data also provides an understanding of how the global (and regional) climate system may respond to large changes in climate forcing (Jansen et al., 2007). Paleoclimate research has focussed on several time periods. These include those climates prior to the Quaternary period, such as the Eocene (55-34 million years ago) where global mean surface air temperatures were more then $10^{\circ} \mathrm{C}$ warmer than today (see $\mathrm{Hu}$ ber, 2008, 2009; Hollis et al., 2009). Also, other paleoclimate studies have focussed primarily on the representation of climate during the Last Glacial Maximum (see for example Drost et al., 2007) and the Mid-Holocene (Hall and Valdes, 1997), which look at the climate response to extensive ice sheets and changes in the Earth's orbital parameters.

Within the last two decades, the development of the Paleoclimate Modeling Intercomparison Project (PMIP) was undertaken to compare the model representations of the climate 21000 (Last Glacial Maximum) and 6000 (Mid-Holocene) years ago with the available paleoclimate proxy data (Joussaume and Taylor, 2000). The work presented in this study will focus only on the Mid-Holocene phase of the experiment and the climate of the Southern Hemisphere (SH). The climate of the Mid-Holocene was subjected to different orbital parameters of the Earth around the Sun, which led to differences in the seasonal distribution of insolation across the globe. The difference in insolation at the top-of-the atmosphere, averaged across all of the models used in this study, can be seen in Fig. 1 for the SH. There is a strong decrease in insolation throughout the summer, which extends into autumn. The amount of insolation then begins to increase in late autumn (from the equator) before a rapid increase at high

Published by Copernicus Publications on behalf of the European Geosciences Union. 


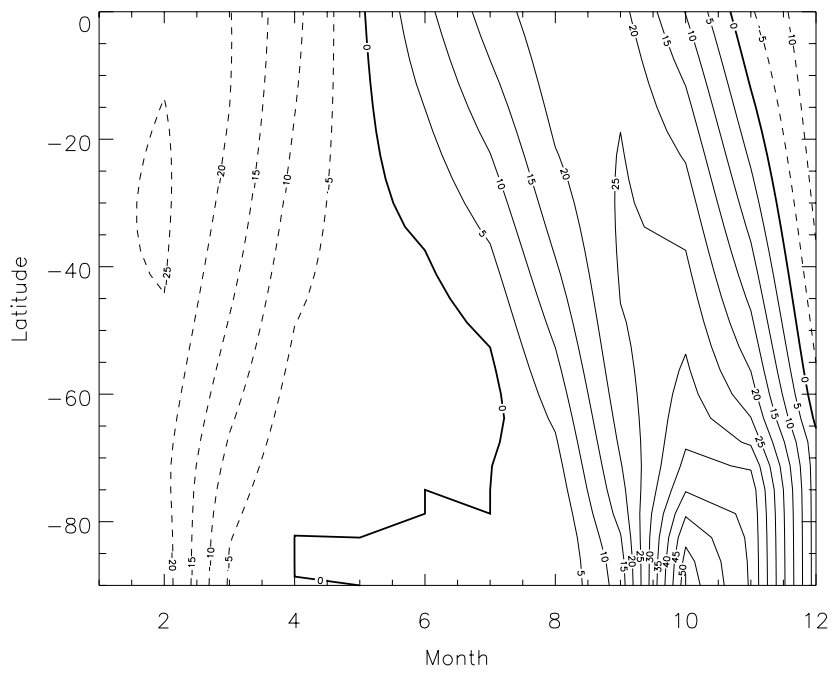

Fig. 1. The difference in zonal, seasonal mean insolation for the Mid-Holocene relative to the pre-industrial control $\left(\mathrm{Wm}^{-2}\right)$, averaged over the five models used in the main analysis. Positive (negative) values are indicated by the solid (dashed) lines. The zero line is the thick black line.

latitudes in the spring. These changes in insolation are likely to have influenced $\mathrm{SH}$ atmospheric variability and climate on a seasonal to inter-annual time-scale.

An important coupled ocean-atmosphere mode of variability, which varies on a seasonal time-scale, is the Semiannual Oscillation (SAO, see van Loon, 1967). The SAO in the SH mid- to high-latitudes is characterised by the contraction and strengthening of the circumpolar trough (CPT) from June to September and December to March with an expansion and weakening from March to June and September to December. An index for the SAO was developed by van Loon (1967) based upon observational data from stations throughout the $\mathrm{SH}$, which used the temperature difference at $500 \mathrm{hPa}$ between $50^{\circ} \mathrm{S}$ and $65^{\circ} \mathrm{S}$. While previous work had identified the semiannual nature of the expansion and contraction of the CPT, the work by van Loon (1967) identified that the atmospheric conditions between $50^{\circ} \mathrm{S}$ and $65^{\circ} \mathrm{S}$ were important in governing the SAO. van Loon (1967) hypothesised that the SAO is a coupled atmosphere/ocean phenomenon but could not confirm this due to a lack of data. Subsequent work by Meehl (1991) and Simmonds and Walland (1998), involving a combination of modelling and observations, was able to confirm that the SAO is a coupled atmosphere/ocean process in the SH extra-tropics. Meehl (1991) even suggested the SAO may play a role in the formation of El-Nino and La Nina events, as well as influencing the Indian monsoon. The relation to ENSO is also highlighted in more recent work by Taschetto et al. (2007), which identified the influence of the SAO in the South Indian, Pacific and Atlantic Ocean sectors. Meehl (1991) also highlighted the difficulty early General Circulation Model (GCM) studies had in representing the SAO when coupled to a slab ocean model of $50 \mathrm{~m}$ depth, which is not deep enough to resolve convective processes that occur in the Southern Ocean and influence the SAO.

Features of the SAO index highlighted in van Loon (1967) and Meehl (1991) are two maxima in the $50^{\circ} \mathrm{S}-$ $65^{\circ} \mathrm{S} 500 \mathrm{hPa}$ temperature difference centred approximately on March and September/October, with a stronger temperature difference in autumn than spring. The SAO can be seen in the National Centers for Environmental Prediction (NCEP)/National Center for Atmospheric Research (NCAR) reanalysis data (Kalnay et al., 1996) (see Fig. 2, black solid line), with the characteristic peaks in March and October. Meehl et al. (1998) and Simmonds and Jones (1998) used NCEP/NCAR reanalysis data to show that the amplitude of the September peak reduced after 1979 causing enhanced cyclonic activity in May-July and November-December with decreased activity in August-September. Further work by van Loon et al. (1993) confirmed that a change in the CPT variability occurred around 1979 and this was not due to improved observations after 1979. Also, observational work by Van den Broecke (2000a,b) has shown that the weakening of the amplitude of the SAO (highlighted in Meehl et al., 1998) resulted in changes to Antarctic cloudiness and wind speed as well as warming (cooling) in Antarctic surface air temperatures in the contracted (expanded) phases of the SAO in March/April and September/October (December/January and June/July).

However, the difference alone is not a good proxy for the strength of the CPT, as highlighted in Walland and Simmonds (1999), as cyclone activity in spring is generally stronger than in autumn in the SH. Another index for identifying the SAO, used by Meehl et al. (1998), is the difference in zonal, annual mean sea level pressure between $50^{\circ} \mathrm{S}-65^{\circ} \mathrm{S}$ (from now $\triangle \mathrm{SLP}$ ) and can be seen in Fig. 3 for the NCEP data. The strongest value of $\triangle$ SLP occurs in October $(21.96 \mathrm{hPa})$, which is slightly higher than in March $(21.78 \mathrm{hPa})$. The SAO can also be seen in the zonal mean SLP field as a function of latitude and month (see Walland and Simmonds, 1999), as in Fig. 4a. The NCEP data (Fig. 4a) have two lows centred on March and October, at $65^{\circ} \mathrm{S}$, with the spring low stronger $(982.0 \mathrm{hPa})$ than in autumn $(984.6 \mathrm{hPa})$. Therefore, despite the apparent stronger baroclinicity in autumn (larger $500 \mathrm{hPa}$ temperature difference between $50^{\circ} \mathrm{S}-65^{\circ} \mathrm{S}$ ) the CPT is deeper in spring than in autumn. However, using seasonally averaged data may not be a good indicator of the baroclinicity of the atmosphere throughout that season as discussed in Simmonds and Lim (2009) and also reduced static stability in spring may lead to increased cyclone activity and a strengthened CPT (Walland and Simmonds, 1999). The CPT also varies at interannual time scales (see Kidson, 1999) and may also be sensitive to changes in the Earth's orbital parameters.

Leading modes of atmospheric variability have also been identified using an Empirical Orthogonal Function (EOF) analysis (see Thompson and Wallace, 2000, as an example). 
The EOF analysis was carried out using NCEP reanalysis data (from 1971-2000) defined on a latitude/longitude grid with a spacing of $2.5^{\circ}$ between $20^{\circ} \mathrm{S}-80^{\circ} \mathrm{S}$. Gridded data were area-weighted to account for convergence of the meridians. Unrotated EOFs were used, as the Southern Annular Mode (SAM, see below) pattern is most clearly identified in the unrotated EOF analysis, and for consistency with other studies (e.g. Thompson and Wallace, 2000; Kidston et al., 2009). The three leading modes of SH interannual variability (with the seasonal cycle removed) have been calculated from the NCEP/NCAR reanalysis data for monthly mean Sea Level Pressure (SLP) and can be seen in Fig. 5. These leading modes of SLP variability are:

1. Southern Annular Mode, SAM: Fig. 5a, also known as the "high latitude mode" (see Karoly, 1990) describes $23.0 \%$ of the variability in SLP and is the leading EOF. The pattern in Fig. 5a exhibits a wavenumber 3 pattern but shows quite a strong zonal symmetry as also noted in Kiladis and Mo (1998).

2. South Pacific Dipole, SPD: Fig. 5b shows a strong forcing from the tropical Pacific with a dipole in SLP variability in the South Pacific near Antarctica and describes $8.8 \%$ of SLP variability (the term "South Pacific Dipole" is taken from Drost et al., 2007). The pattern in Fig. 5b has also been referred to as the Pacific-South America 1 (PSA1) teleconnection in Mo (2000) as there is a wave train from the Pacific, around the tip of South America and into the South Atlantic. Renwick (2002, 1998), Drost et al. (2007), Kiladis and Mo (1998) and Mo (2000) have all shown EOF2 is sensitive to ENSO forcing.

3. Wavenumber $3 /$ Wave train, W: This pattern (describing $7.1 \%$ of the variability in SLP), see Fig. 5c, appears to show two features: (i) a strong wave number 3 pattern with a less zonally symmetric circulation than the SAM and (ii) a wave train originating near the North Tasman Sea propagating around Antarctica and into the South Atlantic. The pattern may be a variant on the SAM given in Fig. 5a but may also be forced by ENSO as suggested in Renwick and Revell (1999) and Drost et al. (2007).

The SAM varies on monthly, seasonal and interannual time-scales (see Kidson, 1999; Kidston et al., 2009; Jones et al., 2009, and references therein) and has been shown to be sensitive to changes in atmospheric greenhouse-gas concentrations and SH ozone depletion (Fogt et al., 2009; Miller et al., 2006; Perlwitz et al., 2008). Therefore, the SAM may show some sensitivity to the changes in seasonal insolation during the Mid-Holocene relative to today. Also, previous work by Zheng et al. (2008) and Chiang et al. (2009) (and references therein) have both shown a reduced ENSO variance in the Mid-Holocene, which may therefore influence

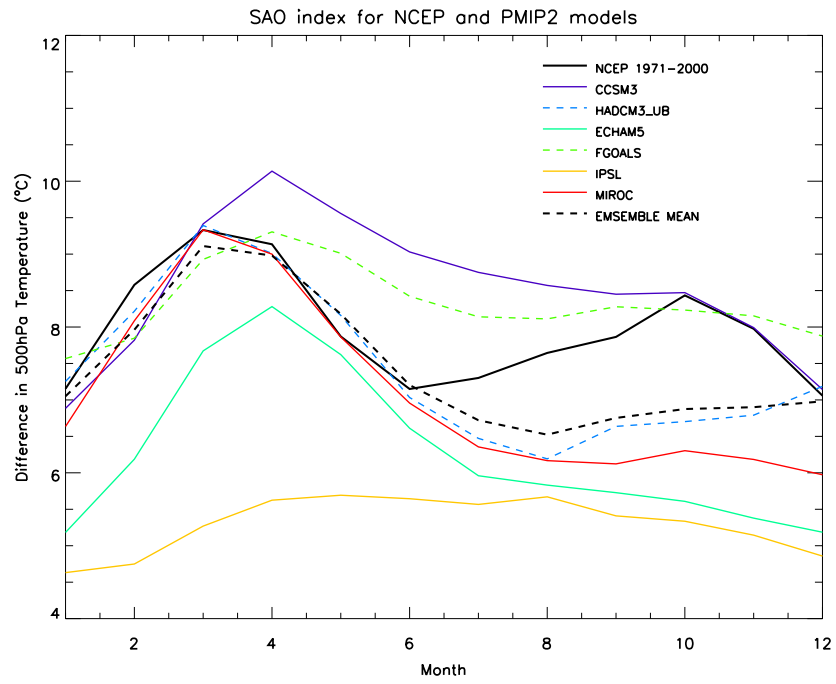

Fig. 2. The SAO index $(500 \mathrm{hPa} \Delta T)$ for NCEP data and all of the available and stable (see Braconnot et al., 2007) models from PMIP2 control run $\left({ }^{\circ} \mathrm{C}\right)$. Refer to Table 1 for more details on each model.

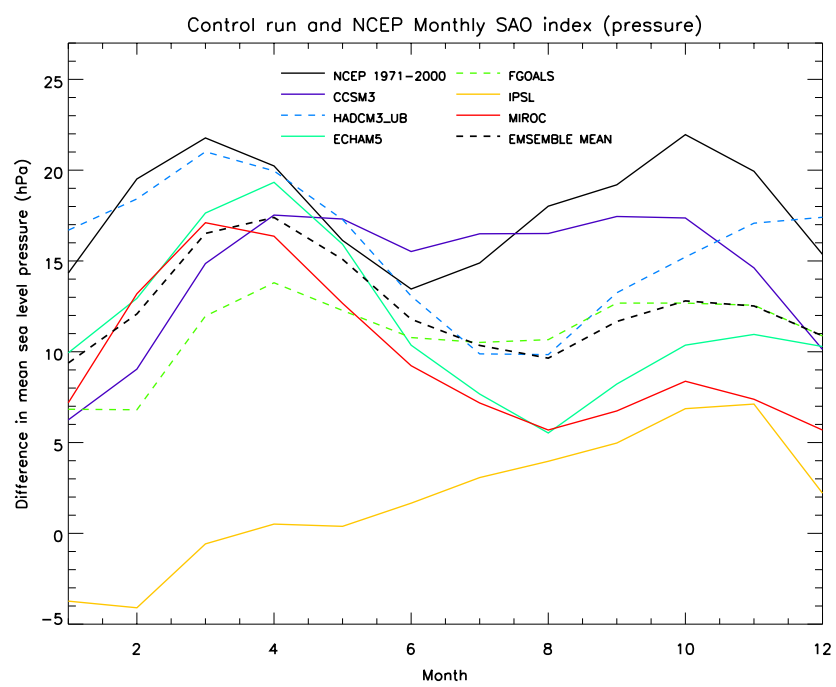

Fig. 3. Another measure of the SAO index $(\triangle \mathrm{SLP})$ for NCEP data and all of the available and stable models (see Braconnot et al., 2007) from the PMIP2 control run (hPa). Refer to Table 1 for more details on each model.

the modes of variability in each model and particularly the SPD and $\mathrm{W}$ modes.

Based on the insolation changes given in Fig. 1, we would expect to see a weaker CPT in summer to early winter with a strengthening in late winter into spring. However, as there is little overall change in the annual mean insolation (Braconnot et al., 2007), we would expect there to be little change in the interannual atmospheric variability in the Mid-Holocene compared to the present day. 
Table 1. Model characteristics as also given in Braconnot et al. (2007) for the models used in this study.

\begin{tabular}{llll}
\hline $\begin{array}{l}\text { Model Name } \\
(\text { PMIP2 database })\end{array}$ & $\begin{array}{l}\text { Model Name } \\
\text { in the text }\end{array}$ & $\begin{array}{l}\text { Atmosphere } \\
\text { resolution [lon } \times \text { lat] } \\
(\text { levels })\end{array}$ & $\begin{array}{l}\text { Ocean } \\
\text { resolution [lon } \times \text { lat] } \\
\text { levels })\end{array}$ \\
\hline CCSM3 & CCSM3 & T42 $(26)$ & $1^{\circ} \times 1^{\circ}(40)$ \\
ECHAM5-MPIOM1 & ECHAM5 & T31 $(19)$ & $1.875^{\circ} \times 0.84^{\circ}(40)$ \\
FGOALS-g1.0 & FGOALS & {$\left[2.8^{\circ} \times 2.8^{\circ}\right](26)$} & $1^{\circ} \times 1^{\circ}(33)$ \\
IPSL-CM4-V1-MR & IPSL & {$\left[3.75^{\circ} \times 2.5^{\circ}\right](19)$} & $2^{\circ} \times 0.5^{\circ}(31)$ \\
MIROC3.2 & MIROC & T42 $(20)$ & $1.4^{\circ} \times 0.5^{\circ}(43)$ \\
UBRIS-HadCM3M2 & HadCM3_UB & {$\left[3.75^{\circ} \times 2.5^{\circ}\right](19)$} & $1.25^{\circ} \times 1.25^{\circ}(20)$ \\
\hline
\end{tabular}

Table 2. Spatial correlation coefficients for each of the PMIP2 models used in this analysis and the 1971-2000 NCEP data. Columns 2-4 (5-7) are the correlation coefficients between the NCEP data and the control (Mid-Holocene, MH) run.

\begin{tabular}{lcccccc}
\hline $\begin{array}{l}\text { Mode } \rightarrow \\
\text { Model } \downarrow\end{array}$ & SAM & SPD & W & MH SAM & MH SPD & MH W \\
\hline CCSM3 & 0.97 & 0.82 & 0.59 & 0.96 & 0.88 & 0.61 \\
ECHAM5 & 0.97 & 0.52 & 0.49 & 0.96 & 0.46 & 0.39 \\
FGOALS & 0.90 & 0.91 & 0.74 & 0.91 & 0.90 & 0.73 \\
HadCM3_UB & 0.97 & 0.87 & 0.78 & 0.97 & 0.89 & 0.76 \\
MIROC & 0.95 & 0.64 & 0.34 & 0.95 & 0.23 & 0.58 \\
\hline
\end{tabular}

The PMIP2 literature to date has primarily focussed on the climate during the Mid-Holocene and Last Glacial Maximum for the Northern Hemisphere (for example Laine et al., 2009) and the tropics (for example Marzin and Braconnot, 2009). Only the work by Rojas et al. (2009) (for the LGM) has focussed on the SH. The work presented here will address the changes in seasonal and interannual variability in the $\mathrm{SH}$, arising from differences in the Earth's orbital parameters associated with the Mid-Holocene period 6000 years before present. Section 2 compares the PMIP2 "pre-industrial" model output to reanalysis data to assess the representation of the SAO. Section 3 compares the Mid-Holocene runs for the chosen PMIP2 models to their respective control phases (with respect to the SAO) and Sect. 4 identifies the changes in surface air temperature and precipitation arising from any changes in the SAO. Section 5 gives the results of EOF analysis on the SH SLP and how the leading modes of SH, lowfrequency climate variability may (or may not) have changed during the Mid-Holocene. The conclusions are given in Sect. 6 .

\section{Verifying PMIP2 control simulations}

\subsection{Data and model simulations}

A selection of six models were used from the PMIP2 database, which are given in Table 1 along with their vertical and horizontal resolution (a more comprehensive description of these models can be found in the reference list of Table 2 in Braconnot et al., 2007). The six models in Table 1 were chosen because they had the available diagnostics to analyse the SAO, while also having very little drift in the surface air temperature, implying the models were in near-surface equilibrium.

To test the capability of each model to represent current climate, each was compared to the NCAR/NCEP reanalysis data. Variables used from the NCEP reanalysis were the air temperature at $500 \mathrm{hPa}$ and mean sea level pressure, between the years 1971-2000. As already described in Sect. 1, previous work has identified a shift in the strength of the SAO (after 1979) around the September/October maximum (see Meehl et al., 1998). Since the work presented in this paper focuses on differences between present day and the MidHolocene, the NCEP data will be averaged across the SAO transition.

\section{$2.250^{\circ} \mathrm{S}-65^{\circ} \mathrm{S}: 500 \mathrm{hPa}$ temperature difference}

As described in Sect. 1, an index for the SAO was originally suggested by van Loon (1967) and used in subsequent studies to define the presence of the SAO in the SH. The zonal mean temperature differences between $50^{\circ} \mathrm{S}$ and $65^{\circ} \mathrm{S}$, averaged over all years for each month of the control run at $500 \mathrm{hPa}$ (from now $500 \mathrm{hPa} \Delta T$ ) can be seen in Fig. 2 for each of the PMIP2 models listed in Table 1. The NCEP 1971-2000 mean is given as the solid black line and the ensemble mean as the black dashed line.

The models generally represent the autumn peak in the $500 \mathrm{hPa} \Delta T$ much better than the spring maximum, with 
(a) NCEP

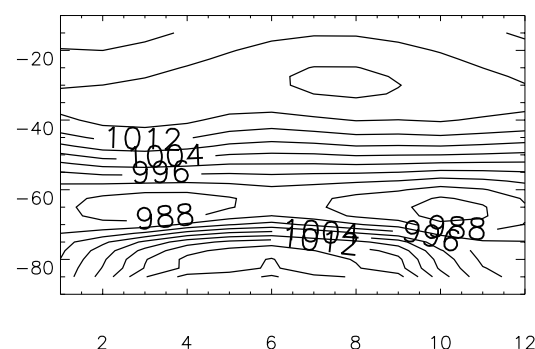

(c) HadCM3_UB

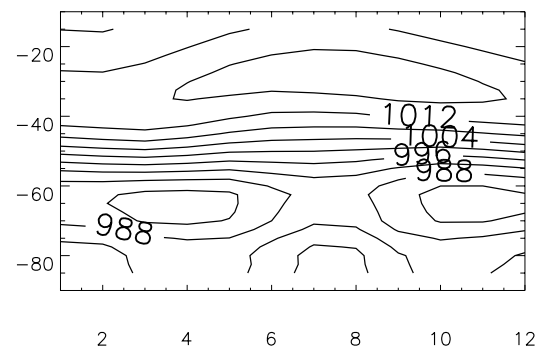

(e) FGOALS

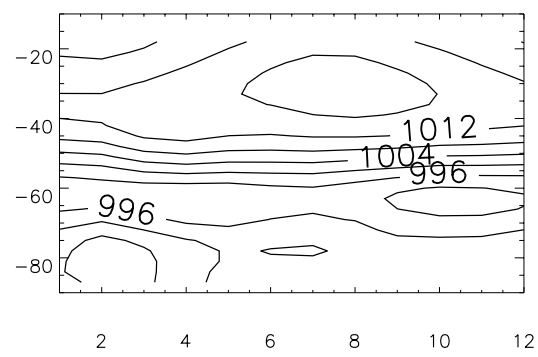

(g) MIROC

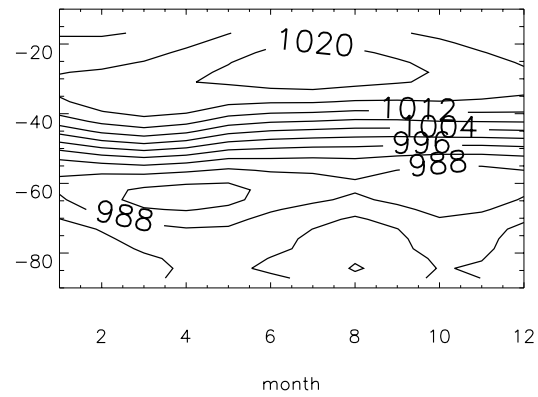

(b) $\operatorname{ccs} 3$

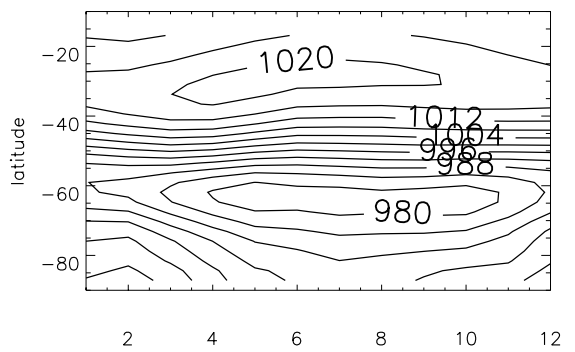

(d) ECHAM5

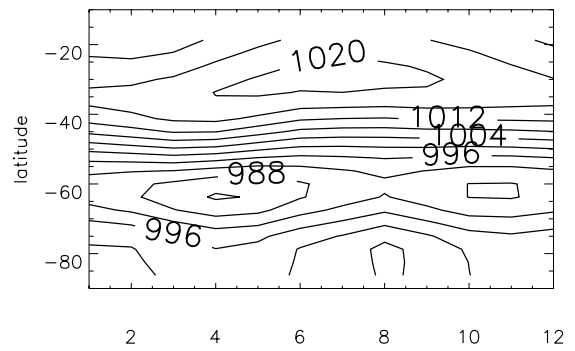

(f) IPSL

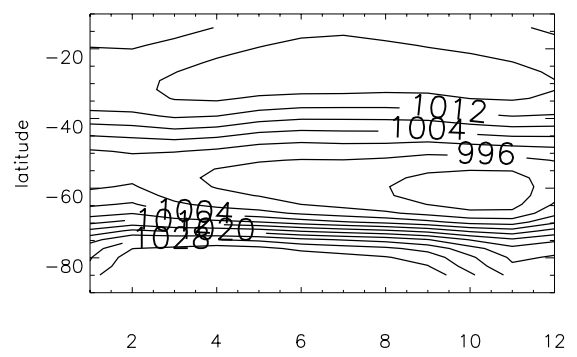

(h) ENSEMBLE MEAN (no IPSL)

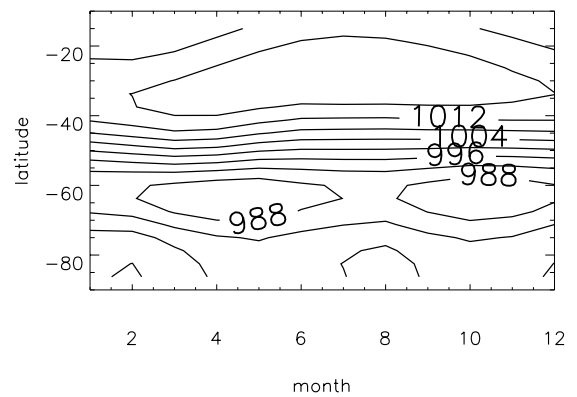

Fig. 4. Zonal mean sea level pressure (hPa) from re-analysis data and the PMIP2 control run for (a) NCEP (re-analysis), (b) CCSM3, (c) HadCM3_UB, (d) ECHAM5, (e) FGOALS, (f) IPSL, (g) MIROC and (h) the ensemble mean (without IPSL included) for each calendar month. Refer to Table 1 for details of each model.

the ensemble mean (without the IPSL model) $500 \mathrm{hPa} \Delta T$ comparing well with the NCEP data between January and June. The October peak is very poorly represented and the ensemble mean $500 \mathrm{hPa} \Delta T$ is lower than NCEP by $0.5-$ $1.0^{\circ} \mathrm{C}$ as also noted in work by Raphael and Holland (2006) and Bracegirdle et al. (2008). The CCSM3 and FGOALS models generally have a higher temperature difference than NCEP and also have the autumn maximum a month too late, however the spring maximum is comparable with the NCEP data. HadCM3_UB, ECHAM5 and MIROC are unable to represent the October maximum in $500 \mathrm{hPa} \Delta T$, however HadCM3_UB and MIROC do show a slight increase in the difference during spring while giving a good representation of the autumn maximum. ECHAM5 displays some of the SAO features but has an April maximum and almost no SAO signal in spring.

According to Raphael and Holland (2006), the poor represnentation of the spring peak in $500 \mathrm{hPa} \Delta T$ in the GCMs can be attributed to a poor representation of the SST around $50^{\circ} \mathrm{S}$, which agrees with Drost et al. (2007) (and 
(a)

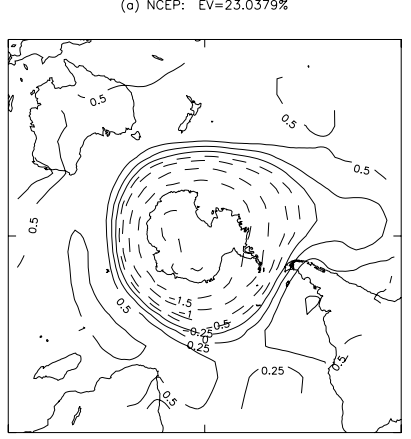

(b)

(b) NCEP: $E V=8.81320 \%$

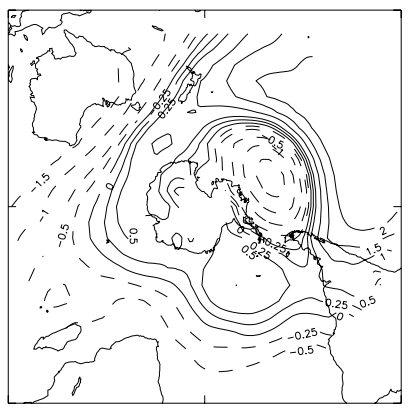

(c)

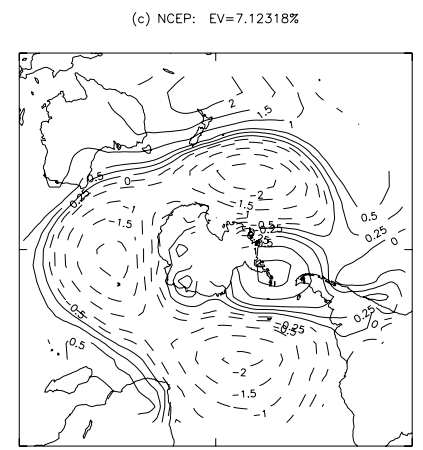

Fig. 5. The three leading EOFs from the 1971-2000 monthly mean NCEP SLP data. (a) SAM, (b) SPD and (c) W. The variation described by each EOF is also given in the figure title. Negative values are dashed and positive values are solid lines.

referencs therein). Extensive work by Randall et al. (2007) (and references therein) has shown that the AR4 ensemble of GCMs has large errors in and around the Antractic Circumpolar Current and agrees with the assessments of Raphael and Holland (2006) and Drost et al. (2007). The seasonality of the PMIP2 SSTs around $50^{\circ} \mathrm{S}$ is out of phase with the HadSST2 dataset (HadSST2 produced by Rayner et al., 2006) by one month in spring (not shown) and is likely to be the cause of the poor representation of the spring $500 \mathrm{hPa}$ $\Delta T$ (further information can be found in the interactive discussion pages, response to reviewer 2).

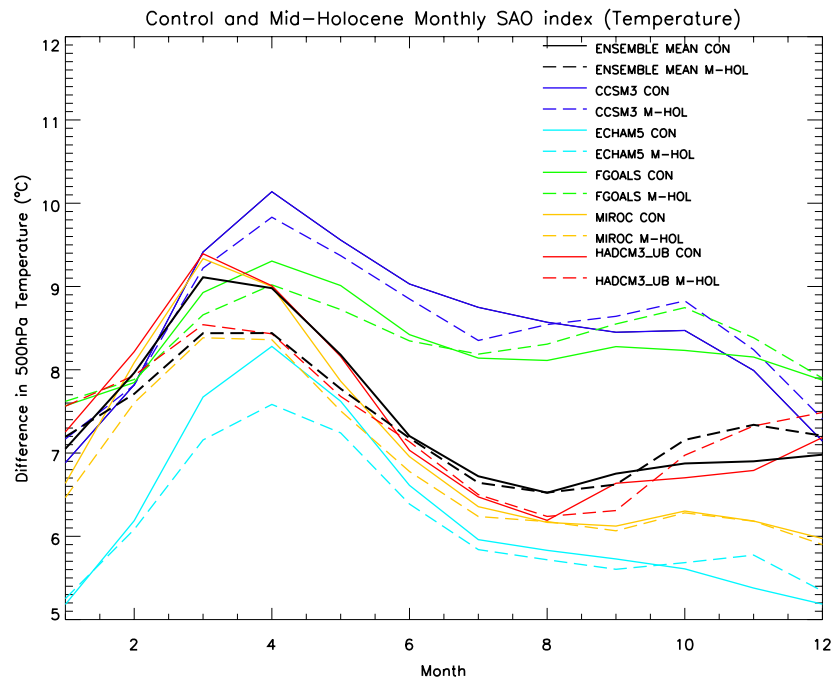

Fig. 6. The $\mathrm{SAO}$ index $(500 \mathrm{hPa} \Delta T)$ for all of the available and stable (see Braconnot et al., 2007) models from the PMIP2 control run (solid lines) and Mid-Holocene runs (dashed lines) $\left({ }^{\circ} \mathrm{C}\right)$. Refer to Table 1 for more details on each model.

Despite the deficiencies of the PMIP2 models apparent in Fig. 2 they do show some characteristics of the SAO, whereas the IPSL model (yellow line) does not show any characteristics of the $\mathrm{SAO}$ in $500 \mathrm{hPa} \Delta T$ and is generally $2^{\circ} \mathrm{C}$ weaker than NCEP. However, $500 \mathrm{hPa} \Delta T$ is not the only indicator for the presence of the SAO and so the IPSL model was retained until the sea level pressure patterns were analysed.

\section{$2.350^{\circ} \mathrm{S}-65^{\circ} \mathrm{S}$ : mean sea level pressure difference}

As with $500 \mathrm{hPa} \Delta T$, most of the models (apart from FGOALS and IPSL) have a similar magnitude $\triangle$ SLP to the NCEP data in March but lag the NCEP data by one month (which shows in the ensemble mean in Fig. 3). Only HadCM3_UB and MIROC have a maximum $\triangle$ SLP in March. The real difference however is during spring where none of the models represent the October maximum well and even the ensemble mean $\triangle \mathrm{SLP}$ is approximately $10 \mathrm{hPa}$ lower than in the NCEP re-analysis.

The zonal mean sea level pressures as a function of latitude and month have also been plotted for each of the PMIP2 models (and the NCEP/NCAR reanalysis data) in Fig. 4. HadCM3_UB, ECHAM5, FGOALS and MIROC all have two periods (in spring and autumn) where the CPT deepens, however the amount of deepening in each season is very model dependent. The CPT is stronger in spring than in autumn for the NCEP data and the only model with this pattern is FGOALS (Fig. 4e) although the central pressures of each low are too high (characteristic of the weak changes in $500 \mathrm{hPa} \Delta T$ in Fig. 2). HadCM3_UB and ECHAM5 capture the lowest pressure near $65^{\circ} \mathrm{S}$ but the autumn low (for 

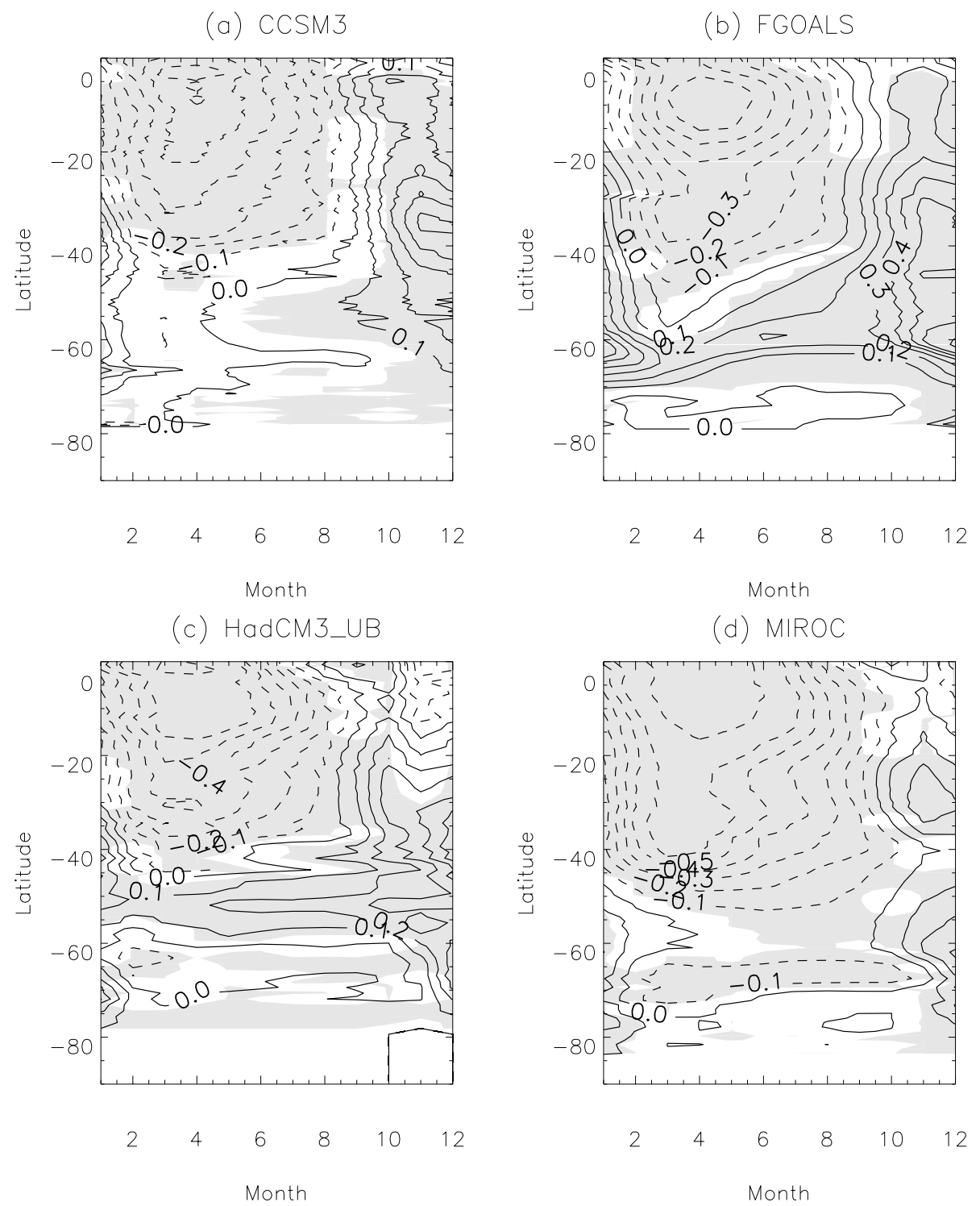

Fig. 7. Zonal mean difference in SST $\left(0^{\circ} \mathrm{S}-90^{\circ} \mathrm{S}\right)$ between the PMIP2 Mid-Holocene and control runs for (a) CCSM3, (b) FGOALS, (c) HadCM3_UB, and (d) MIROC for each calendar month. Refer to Table 1 for more details on each model. Solid (dashed) lines indicate positive (negative) changes and statistically significant changes $(p \leq 0.05)$ are shaded grey.

ECHAM5) is stronger than in spring (which is characteristic of the $500 \mathrm{hPa} \Delta T$ being too weak in spring, see Fig. 2) and both models lag the NCEP data by a month.

CCSM3 and IPSL do not show two distinct low pressure centres during the year (Fig. $4 \mathrm{~b}$ and $\mathrm{f}$, respectively) and the intensity of the CCSM3 low from April to October is too strong. However, CCSM3 does capture some of the features in $500 \mathrm{hPa} \Delta T$ (albeit too strong in April to October) and so will be considered further. IPSL however does not represent any features of the SAO at each of these stages and is removed from the next sections when comparing the control runs to the Mid-Holocene. The ensemble mean SLP in Fig. $4 \mathrm{~h}$ without IPSL is able to capture the magnitude of the pressure minima near $65^{\circ} \mathrm{S}$ but the spring minimum is much weaker than in NCEP (as expected) and the low pressure belt centred on $65^{\circ} \mathrm{S}$ is too broad.

\section{Mid-Holocene SAO}

In this section, $500 \mathrm{hPa} \Delta T$ and changes in the SLP distribution will be analysed to identify the effects of changing the orbital parameters on the SH SAO. The changes in the analysed atmospheric variables were subjected to a t-test to determine statistical significance. The null hypothesis in each case was that the sample means for the Mid-Holocene and the control run were the same and the alternate hypothesis 


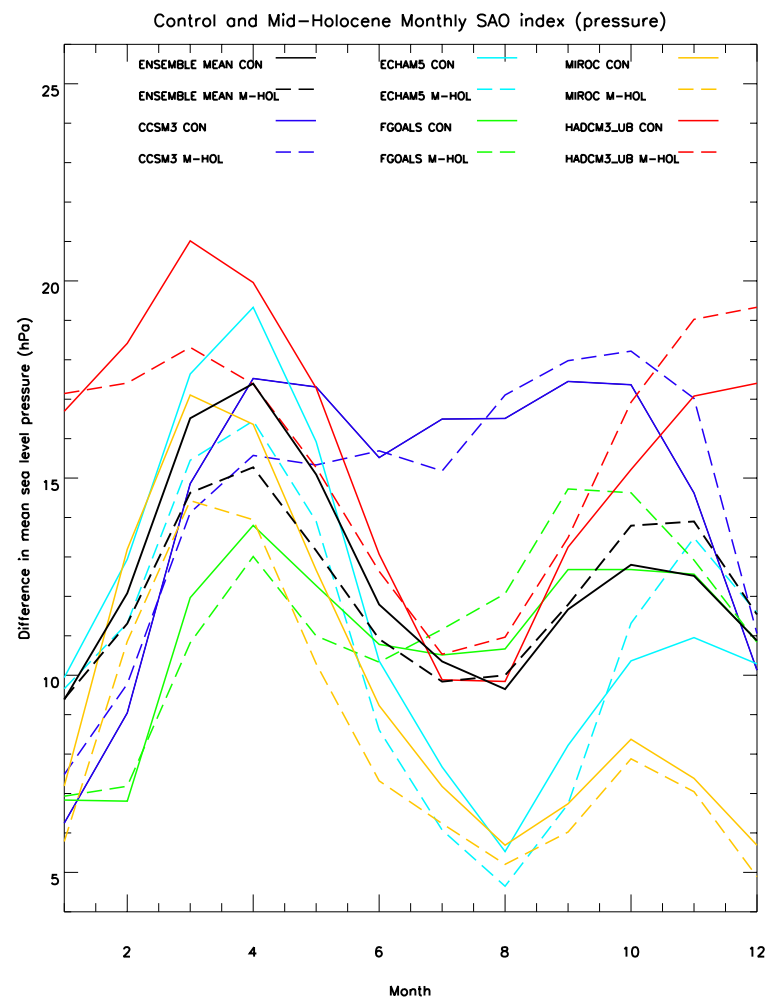

Fig. 8. Another measure of the SAO index $(\triangle \mathrm{SLP})$ for all of the available and stable (see Braconnot et al., 2007) models from the PMIP2 control run (solid lines) and Mid-Holocene runs (dashed lines) (hPa). Refer to Table 1 for more details on each model.

that they were not. If $p \leq 0.05$ we rejected the null hypothesis. Subsequently, the statistically significant changes in atmospheric fields are indicated in the appropriate figures.

\section{$3.150^{\circ} \mathrm{S}-65^{\circ} \mathrm{S}: 500 \mathrm{hPa}$ temperature difference}

The $500 \mathrm{hPa} \Delta T$ SAO index for each of the PMIP2 models and the ensemble mean of those models can be seen in Fig. 6, with solid lines indicating the control run and dashed lines the Mid-Holocene run. The first point of note is the weakening of the autumn peak in $500 \mathrm{hPa} \Delta T$ in all models. Another similarity between models is a strengthening of the spring $500 \mathrm{hPa} \Delta T$ in October-December (September-December for CCSM3 and FGOALS). MIROC however does not show the same increase in $500 \mathrm{hPa} \Delta T$ difference in spring and actually shows a very slight reduction, which is contrary to output from the other models.

The zonal mean response of the model SSTs to the MidHolocene insolation changes in Fig. 1 can be seen in Fig. 7. SST data were available for four of the PMIP2 models CCSM3, FGOALS, HadCM3_UB and MIROC (IPSL was not included). There is a general reduction in SST throughout the SH low- to mid-latitudes in all models from January to June with either a slight warming or no change to high- latitude SST. This contributes to the reduced MAM $500 \mathrm{hPa}$ $\Delta T$ in all models by reducing the equator-to-pole temperature gradient. In late winter/spring however, there is a strong reversal in the mid-latitude SST anomalies and little change at high-latitudes in CCSM3, FGOALS and HadCM3_UB, which suggests an increase in the equator-to-pole temperature gradient and thereby increasing $500 \mathrm{hPa} \Delta T$ during the Mid-Holocene. The exception to this is MIROC (Fig. 7d), which has cooler SSTs persisting well into the spring and only a short period of weak warming in late spring/early summer. The warming (cooling) of low- to mid-latitude SSTs in response to the insolation changes, are likely to be driving the strengthening (weakening) $500 \mathrm{hPa} \Delta T$ during the MidHolocene.

While there are obvious limitations in the model representation of the spring maximum in $500 \mathrm{hPa} \Delta T$ (see Sect. 2.2), the similar responses of each of the models (except MIROC) suggest the strengthening is a result of the changes in orbital parameters and that the $500 \mathrm{hPa} \Delta T$ may have been stronger in spring during the Mid-Holocene than at present.

\section{$3.250^{\circ} \mathrm{S}-65^{\circ} \mathrm{S}$ : mean sea level pressure difference}

Plots for $\triangle$ SLP for each of the PMIP2 models and the ensemble mean can be seen in Fig. 8. The effect of reducing the autumn $500 \mathrm{hPa} \Delta T$ can be seen in all models with a reduction in $\triangle \mathrm{SLP}$ (approximately $2 \mathrm{hPa}$ in March-April) with particularly strong reductions in HadCM3_UB and ECHAM5. The models all have reduced $\triangle$ SLP from March to June, where there is reduced SH insolation at mid- to high-latitudes (see Fig. 1). The results from the PMIP2 models also suggest that the spring $\triangle \mathrm{SLP}$ increases (in agreement with $500 \mathrm{hPa}$ $\Delta T$ ) except in the MIROC model, where there appears to be a reduced SLP difference throughout the year (again in agreement with the MIROC $500 \mathrm{hPa} \Delta T$ result in Sect. 3.1). The strengthened SLP difference corresponds with increased mid- to high-latitude insolation in late winter and spring (see Fig. 1).

The zonal mean change in SLP for each of the PMIP2 models and the ensemble mean, for the Mid-Holocene compared to the control, have been plotted in Fig. 9 for each month of the year. Each of the models (except MIROC) support the notion of increased (reduced) SLP during autumn (spring) between $60^{\circ} \mathrm{S}-80^{\circ} \mathrm{S}$ but also show a dipole feature with decreased (increased) SLP in autumn (spring) between $30^{\circ} \mathrm{S}-50^{\circ} \mathrm{S}$. The increased SLP in autumn between $60^{\circ} \mathrm{S}-80^{\circ} \mathrm{S}$ occurs in all models but the initiation and duration of the increased SLP anomaly is very model-dependent. ECHAM5 and FGOALS (Fig. 9c and d, respectively) suggest that there is a general increase in SLP from the start of the calendar year up to August/September and only in spring does the SLP anomaly become negative. However, ECHAM5 and FGOALS show different effects at $30^{\circ} \mathrm{S}-$ $50^{\circ} \mathrm{S}$ with much stronger negative anomalies in autumn in ECHAM5 than FGOALS. 
(a) $\cos 33$

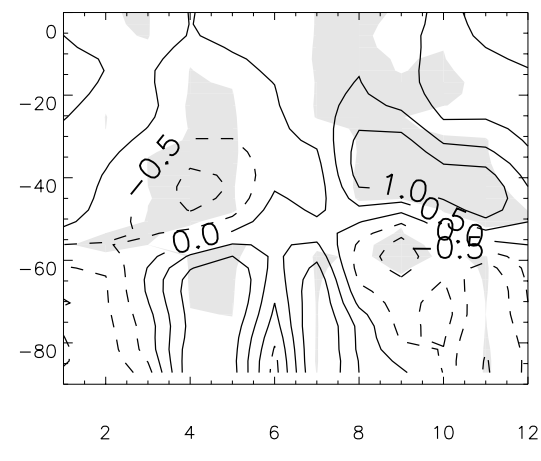

(c) ECHAM5

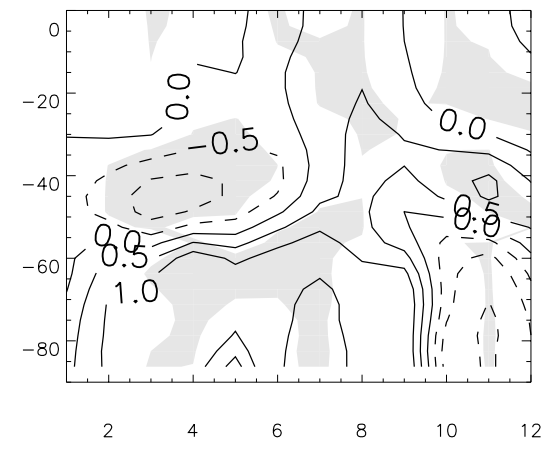

(e) MIROC

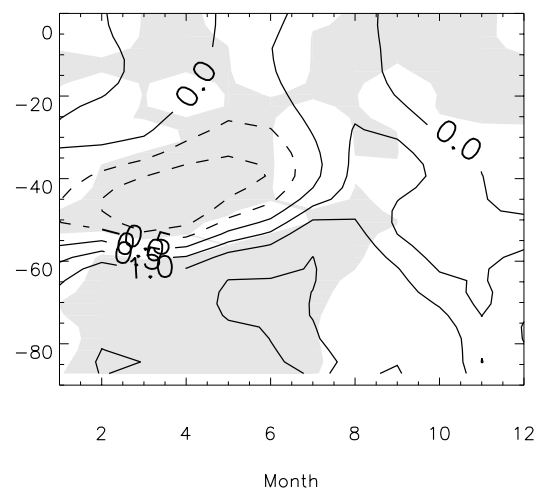

(b) HadCM3_UB

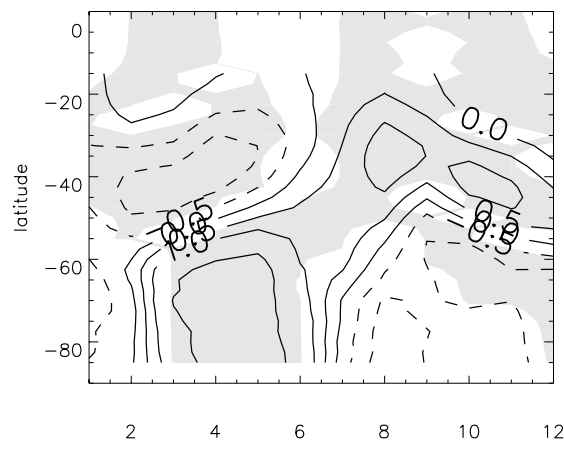

(d) FGOALS

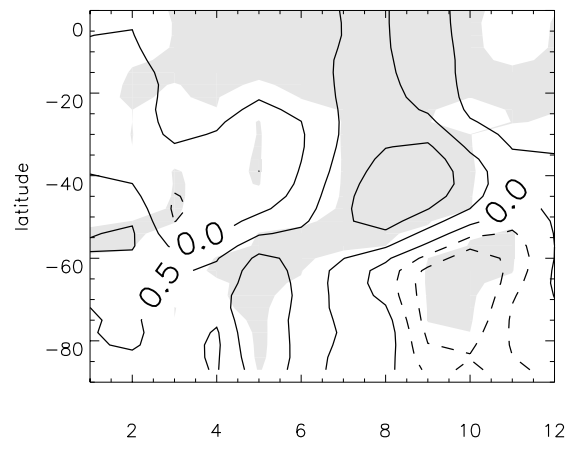

(f) ENSEMBLE MEAN

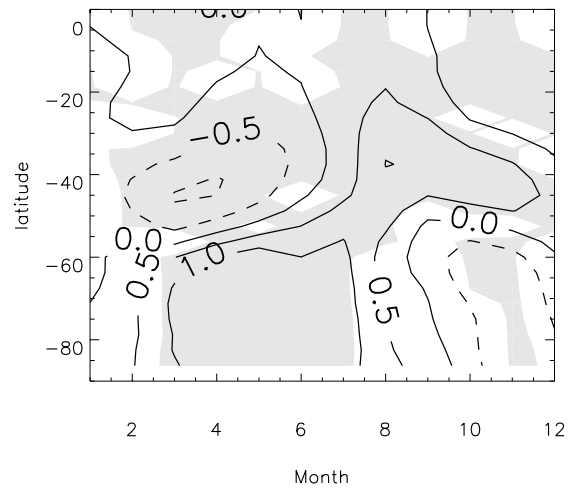

Fig. 9. Zonal mean difference in sea level pressure (hPa) between the PMIP2 Mid-Holocene and control runs for (a) CCSM3, (b) HadCM3_UB, (c) ECHAM5, (d) FGOALS, (e) MIROC and (f) the ensemble mean for each calendar month. Refer to Table 1 for more details on each model. Solid (dashed) lines indicate positive (negative) changes and statistically significant changes $(p \leq 0.05)$ are shaded grey.

Both CCSM3 and HadCM3_UB have decreased SLP between $60^{\circ} \mathrm{S}-80^{\circ} \mathrm{S}$, which starts in late winter, continues into January and February (and even March for CCSM3) but rapidly becomes positive in early- to mid-autumn. Also, both CCSM3 and HadCM3_UB have much more apparent dipoles in SLP between $60^{\circ} \mathrm{S}-80^{\circ} \mathrm{S}$ and $30^{\circ} \mathrm{S}-50^{\circ} \mathrm{S}$.

While the zonal mean SLP plots indicate where the difference between the Mid-Holocene and the control run occur temporally, they do not give a detailed look at the spatial structure of the SLP distribution. As the main differences between the control and Mid-Holocene runs occur in autumn and spring the focus will now move to those seasons. The change in SLP for the Mid-Holocene relative to the control run can be seen in Figs. 10 and 11 for MAM (autumn) and SON (spring), respectively.

The increase in SLP throughout the CPT in MAM is apparent in all the PMIP2 models with decreases in SLP equatorward of the trough. Another similar feature in each of 
(a) $\operatorname{ccs} 3$

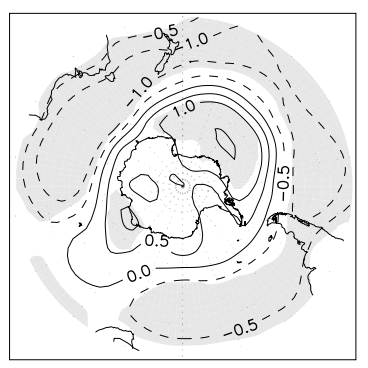

(c) ECHAM5

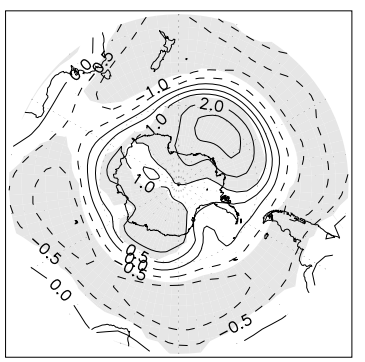

(e) MIROC

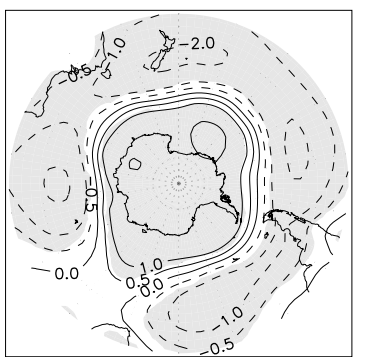

(b) HADCM3_UB

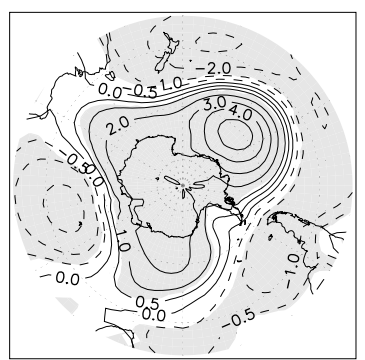

(d) FGOALS

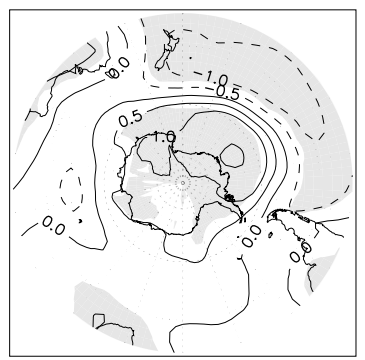

(f) ENSEMBLE MEAN

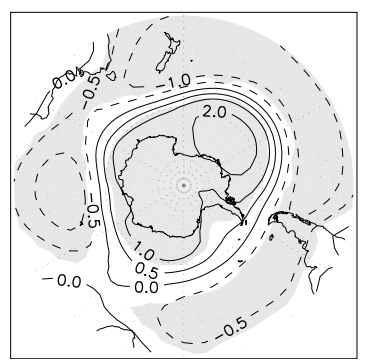

(a) $\operatorname{ccs} 3$

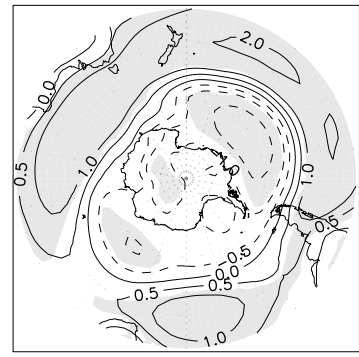

(c) ECHAM5

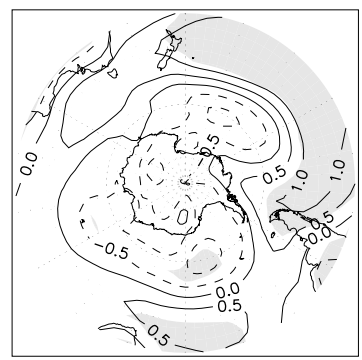

(e) MIROC

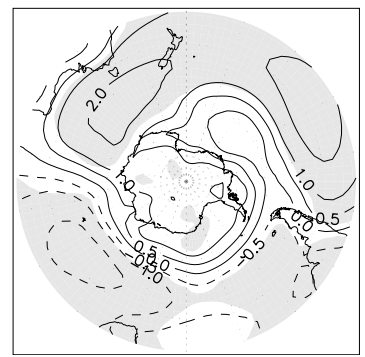

(b) HADCM3_UB

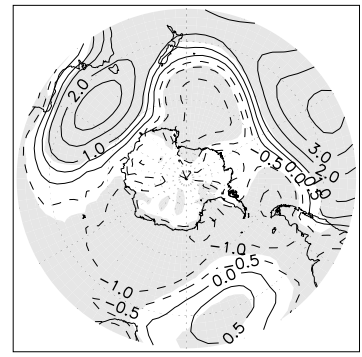

(d) FGOALS

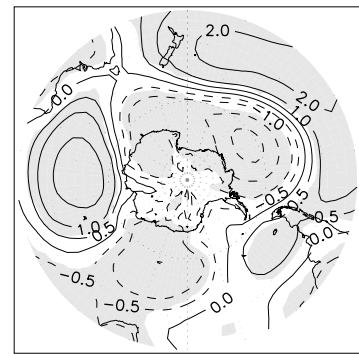

(f) ENSEMBLE MEAN

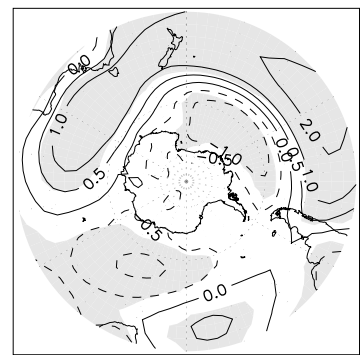

Fig. 10. The MAM mean difference in sea level pressure $(\mathrm{hPa})$ between the PMIP2 Mid-Holocene and control runs for (a) CCSM3, (b) HadCM3_UB, (c) ECHAM5, (d) FGOALS, (e) MIROC and (f) the ensemble mean. Refer to Table 1 for more details on each model. Solid (dashed) lines indicate positive (negative) changes and statistically significant changes $(p \leq 0.05)$ are shaded grey.

the models is an increase in SLP between approximately $180^{\circ} \mathrm{E}$ and $100^{\circ} \mathrm{W}$ and shows as a pressure anomaly of more than $2 \mathrm{hPa}$ in the ensemble mean. Despite these similarities, the patterns of SLP change between the Mid-Holocene and the control run vary considerably between the models. the FGOALS model (Fig. 10d) has very weak reductions in SLP equatorward of the CPT whereas the other four models show much stronger pressure decreases (Fig. 10a-c and e). HadCM3_UB appears to show a particularly strong change in the zonal SLP field (wavenumber 3) whereas the other models generally show the pattern to be more zonally symmetric in comparison (although there are some wave features in each, which show in the ensemble mean).

The structure of the changes in SH SLP for spring are more complex than the autumn changes. The response in CCSM3 (Fig. 11a) has an approximate reverse in the SLP anoma-
Fig. 11. The SON mean difference in sea level pressure (hPa) between the PMIP2 Mid-Holocene and control runs for (a) CCSMS3, (b) HadCM3_UB, (c) ECHAM5, (d) FGOALS, (e) MIROC and (f) the ensemble mean. Refer to Table 1 for more details on each model. Solid (dashed) lines indicate positive (negative) changes and statistically significant changes $(p \leq 0.05)$ are shaded grey.

lies compared to MAM with an enhancement of the CPT and an increase in SLP equatorward of $55^{\circ}-60^{\circ}$ S. CCSM3 has the smallest meridional change in the SLP patterns. Both HadCM3_UB and FGOALS (Fig. 11b and d) have a reduced zonal symmetry for the Mid-Holocene SLP field in a wavenumber 3 pattern, with negative changes in SLP, which suggests a strengthening of the CPT. HadCM3_UB and FGOALS also have higher SLP to the south of Australia and over the South Pacific, however the higher pressure anomalies are displaced further east (west) in HadCM3_UB (FGOALS), which would result in more southwesterly (northwesterly) winds over New Zealand and would have a strong bearing on climate there. The SLP decreases in the CPT are much weaker in ECHAM5 (Fig. 11c) than in CCSM3, HadCM3_UB and FGOALS whereas MIROC is the only model to show a weakening of the CPT in SON. Fea- 
(a) MAM

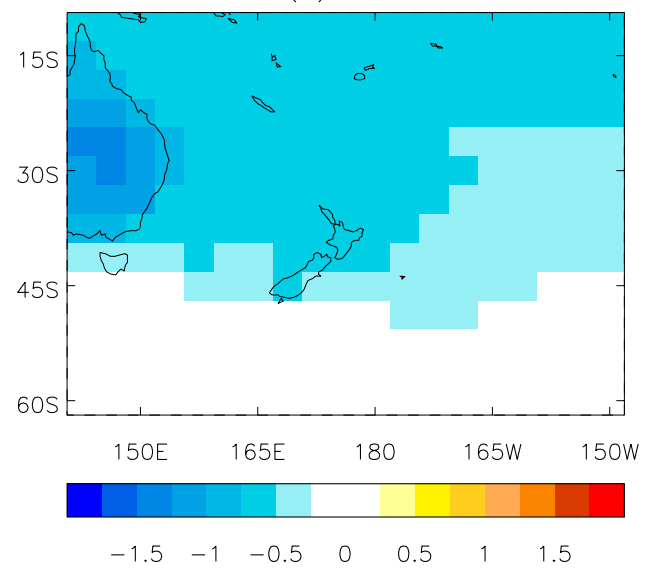

(b) SON

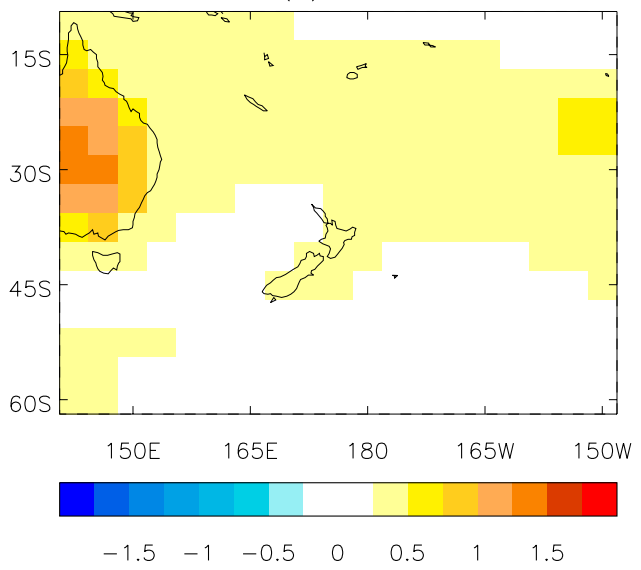

Fig. 12. The ensemble mean change in surface air temperature $\left({ }^{\circ} \mathrm{C}\right)$ between the PMIP2 Mid-Holocene and the control run for (a) MAM and (b) SON. Only statistically significant changes $(p \leq 0.05)$ are shaded. Refer to Table 1 for more details on each model.
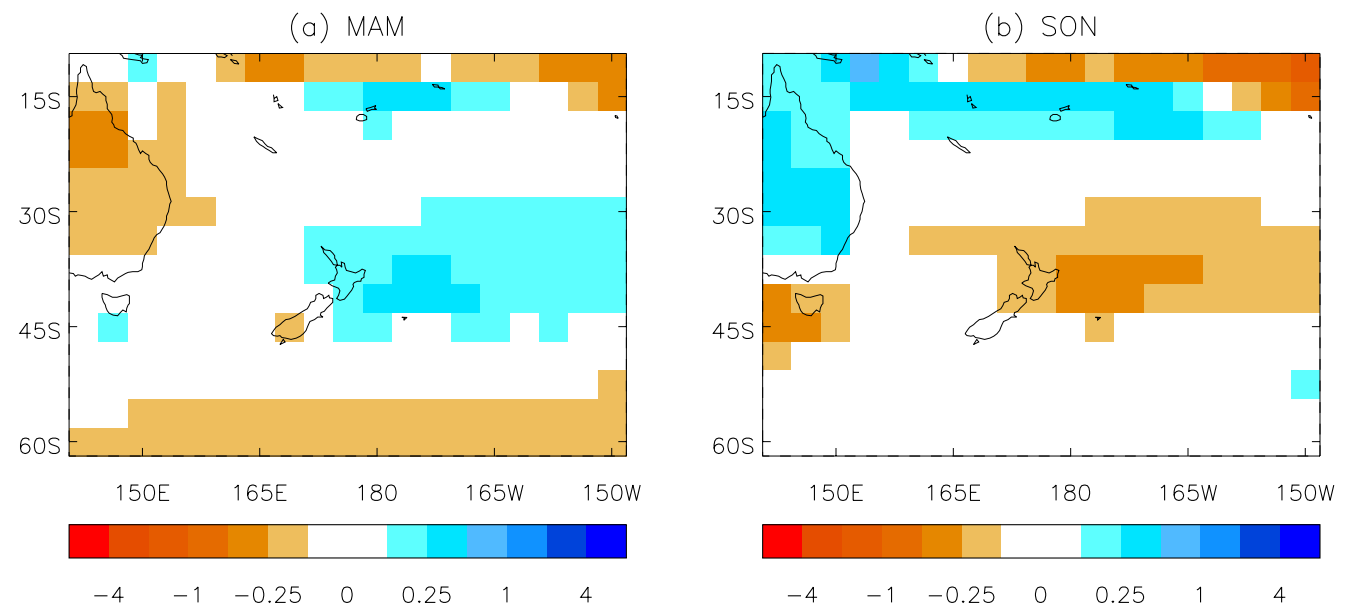

Fig. 13. The ensemble mean change in precipitation $\left(\mathrm{mm} \mathrm{day}^{-1}\right)$ between the PMIP2 Mid-Holocene and the control runs for (a) MAM and (b) SON. Only statistically significant changes $(p \leq 0.05)$ are shaded. Refer to Table 1 for more details on each model.

tures that particularly stand out in the ensemble mean are the increases in SLP to the South of Australia, which extends into the South Pacific Ocean and the enhancement of the CPT (which is compensated slightly by including MIROC).

\section{New Zealand climate in the Mid-Holocene}

The general consensus from the PMIP2 models given in Sect. 3 indicates a weakening of the autumn maximum in the SAO with a strengthening of the spring maximum. As the work undertaken in this study forms the basis for a modelling investigation into New Zealand (NZ) Mid-Holocene climate, some of the changes in surface air temperature and precipitation associated with changes in orbital parameters will be considered. The focus will be on MAM and SON, where there appear to be the larges changes in the wavenumber 2 of the annual SLP cycle. However, the amplitude of the $\mathrm{SAO}$ in the New Zealand region is relatively small compared to the rest of the SH mid-latitudes (see Simmonds, 2003).

\subsection{Surface air temperature}

The ensemble mean change in surface air temperature, for the Mid-Holocene relative to the pre-industrial control run, in the NZ region, can be seen for MAM and SON in Fig. 12a and $b$, respectively. The first point to note is that MAM temperature changes are generally negative and SON temperature changes are generally positive, which agrees with the changes in SH insolation during the Mid-Holocene as shown in Fig. 1. 

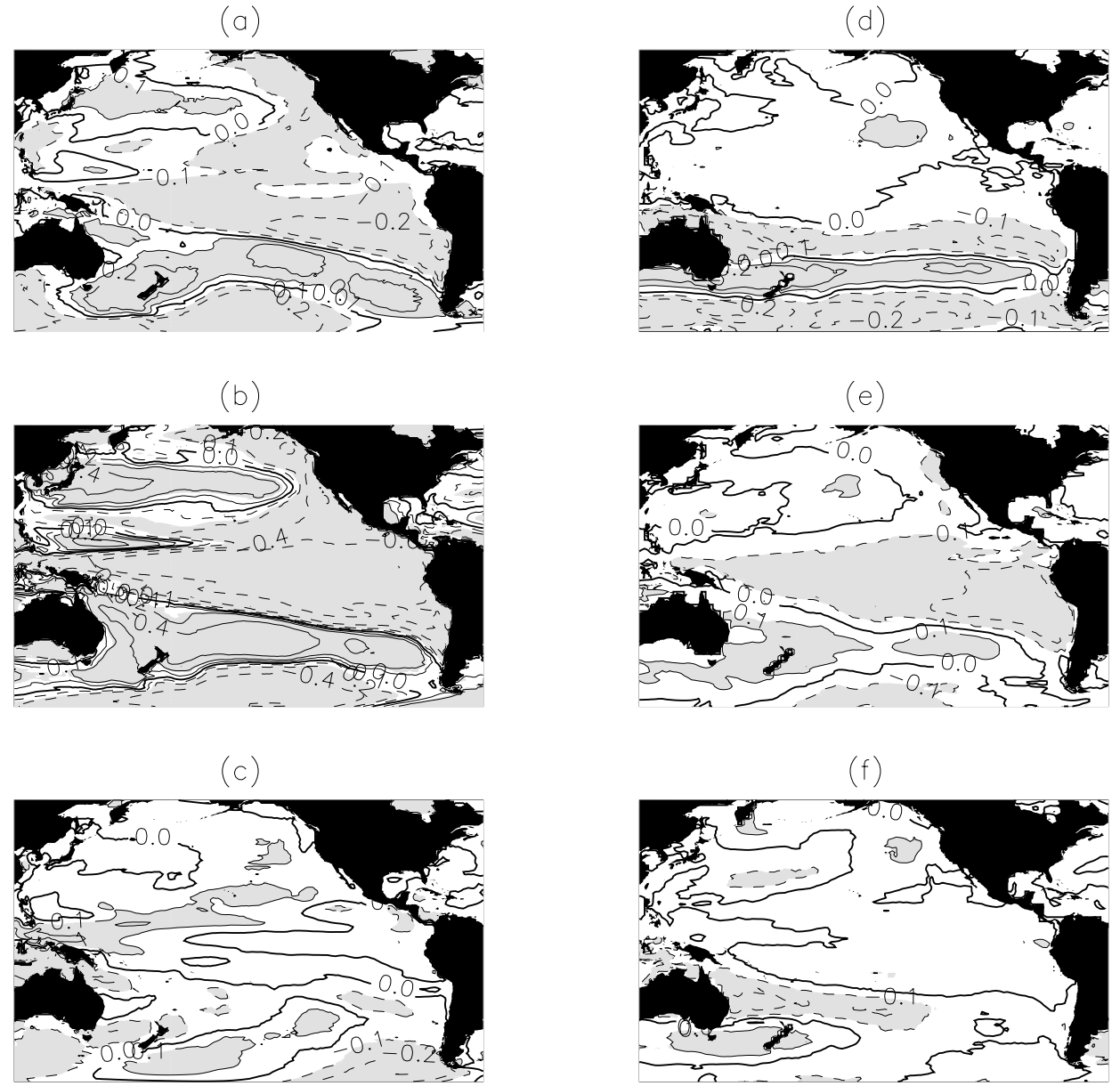

Fig. 14. Correlation of the monthly mean global SSTs with the time series of the three leading EOFs in FGOALS, (a) for SAM, (b) for SPD and (c) for W, and MIROC (d) for SAM, (e) for SPD and (f) for W. Correlation contour intervals are 0.1 with the zero correlation line given as the thick, solid black line and positive (negative) correlations denoted by the solid (dashed) lines. Statistically significant correlations $(p \leq 0.05)$ are shaded in grey.

For MAM, the cooling occurs in all models with some variation to the south of New Zealand in the Southern Ocean (not shown) and each model shows a low pressure anomaly close to NZ. The cooling is rather extensive in all models throughout the region given in Fig. 12a, which suggests the reduced autumn insolation (see Fig. 1) is acting to cool surface temperatures substantially in this region.

In SON there is a general warming throughout the NZ region (Fig. 12b) in particular to the north of NZ and over Eastern Australia. However, due to the locations of the pressure anomalies presented in Fig. 11, there were some local variations from the ensemble mean in each model. HadCM3_UB in particular has strong cooling to the west of NZ with warming along the eastern side and then a further cooling south and east over the ocean. By looking at Fig. 11b, the SLP field has an enhanced wavenumber 3 pattern, which leads to an increase in the prevalence of southwesterly winds at the surface. The southwesterlies cool the western side of NZ but allow warming to the east as a result of a föhn effect. The opposite is true however in the FGOALS model, where the position of the low anomaly is further east, causing air to be drawn from the north and warming over NZ (see Salinger and Mullan, 1999; Kidson, 2000; Kidston et al., 2009, for more details on the influence of flow regimes on NZ temperatures). The importance of this result is that, despite FGOALS and HadCM3_UB both showing a tendency toward enhanced wavenumber 3 activity, the mean climatological positions of those anomalies result in completely different effects on NZ climate.

Overall, the results show persistent cooling in MAM and a warming in SON, however the SON warming depends much more on the position of the SLP anomalies shown in Sect. 3.2 than in MAM when there appears to be a more general cooling. 
Table 3. The variability described by the three leading EOFs for the NCEP model and the pre-industrial control phase of the PMIP2 models (columns 2-4) and for the PMIP2 models for the Mid-Holocene (columns 5-7, denoted MH).

\begin{tabular}{lcccccc}
\hline $\begin{array}{l}\text { Mode } \rightarrow \\
\text { Model } \downarrow\end{array}$ & SAM \% & SPD \% & W \% & MH SAM \% & MH SPD \% & MH W \% \\
\hline NCEP & 23.0 & 8.8 & 7.1 & - & - & - \\
CCSM3 & 31.0 & 6.4 & 7.5 & 30.0 & 6.4 & 7.4 \\
ECHAM5 & 34.9 & 8.1 & 5.7 & 35.2 & 8.2 & 5.9 \\
FGOALS & 23.9 & 11.6 & 7.3 & 23.6 & 10.7 & 7.3 \\
MIROC & 36.4 & 6.4 & 5.6 & 36.9 & 6.1 & 6.4 \\
HadCM3_UB & 28.3 & 5.9 & 6.7 & 27.6 & 6.7 & 6.1 \\
\hline
\end{tabular}

\subsection{Precipitation}

The ensemble mean change in precipitation for the MidHolocene compared to the control run can be seen in Fig. 13a and $\mathrm{b}$ for MAM and SON, respectively, in the NZ region. Unlike surface air temperature, the changes in precipitation show more small scale structure but do highlight some of the characteristics identified previously in Sects. 3.2 and 4.1.

The ensemble mean for MAM (Fig. 13a) indicates a moistening around NZ with more precipitation over the North Island, however when considering the individual models in more detail some of the effects of the SLP anomalies in Fig. 10 become more apparent. For example, a low pressure anomaly to the east of NZ in HadCM3_UB during MAM (Fig. 10b) leads to increased surface easterlies which causes increased precipitation along the eastern coast of NZ and drying to the west (not shown) and agrees with the flow regime identified in Salinger and Mullan (1999). However, precipitation is not governed by SLP patterns alone and there is a large amount of inter-model variation over NZ, although four of the five models used show increased precipitation over the North Island, agreeing with the reduction in SLP in Fig. 10.

For the SON ensemble mean (Fig. 13b) precipitation there appears to be reducing over much of NZ with stronger drying in the north than in the south. Four of the five models show drying throughout most of NZ with the only exception to this being MIROC, which has an increase in precipitation over the North Island and little or no drying over the South Island. The precipitation changes for MIROC during SON are similar to those of MAM, which agrees with the analysis in Sect. 3 that MIROC is the only model demonstrating a weakening of the SAO during the Mid-Holocene in both autumn and spring.

\section{Seasonal to interannual variability}

Sections 2 and 3 have focussed on the abilities of each of the PMIP2 models to represent the SAO and to identify how it may have changed in the Mid-Holocene compared to present day. There is a high degree of variation between the models particularly in the SLP fields (see Figs. 10 and 11). In this section we consider how well the models represent lowfrequency variability in SLP and identify how that variability may have changed under different orbital parameters during the Mid-Holocene.

\subsection{Variability in PMIP2 models: pre-industrial control run}

To compare the PMIP2 models to NCEP data, the three leading EOFs of monthly mean sea level pressure (over all 100 years, for all months of the year and with the seasonal cycle removed) were analysed for each model given in Table 1 (except IPSL). To understand how well the models represented the spatial patterns of variability, the correlation between the NCEP and model data (for each mode) was calculated for all models. The correlation coefficients are given in Table 2.

All models show a high degree of spatial correlation with the SAM in the NCEP data, for the control runs. The spatial correlations generally drop for the SPD and W modes with FGOALS and HadCM3_UB giving the highest overall correlation with NCEP across the three modes and with ECHAM5 and MIROC showing the lowest correlation after the SAM. Following Table 2, the percentage of the variance described by each of the first three EOFs for NCEP and the five models under discussion are shown in Table 3 . The first point to note is that ECHAM5 and MIROC are dominated by the SAM with both models describing more than $34 \%$ of the variance for that mode. They also describe less variance in the SPD and $\mathrm{W}$ modes than in the NCEP data (although ECHAM5 has a high percentage value for SPD, but a low spatial correlation with NCEP). These models (ECHAM5 and MIROC) seem to be too SAM dominated, and poor at representing the structures associated with ENSO forcing.

$31 \%$ of the total variation in the CCSM3 SLP field is described by the SAM (Table 3). The SLP field in CCSM3 also has high spatial correlations with NCEP for the SPD (higher than in MIROC or ECHAM5) and W modes, see Table 2. The other feature of CCSM3 is that it describes more of the SH variability in the $\mathrm{W}$ mode than the SPD mode in the control run. HadCM3_UB also describes more variability in W than SPD but has a very high spatial correlation with the NCEP modes. Finally, FGOALS appears to be the 
most capable model at representing the SAM compared to NCEP (see Table 3) while also distributing a large amount of the remaining variability in both the SPD and W modes (although the SPD mode is more dominant than in the NCEP data). FGOALS and HadCM3_UB both show the highest degree of spatial correlation with the NCEP modes and appear to be the best models at representing the leading $\mathrm{SH}$ modes of variability (SAM, SPD, W). However, HadCM3_UB describes more variability in the $\mathrm{W}$ mode than the SPD mode and has a tendency toward the SAM.

To identify how the models respond to ENSO, we produced correlation maps of the EOF time series for SAM, SPD and W with monthly SST anomalies throughout the globe for FGOALS and MIROC. FGOALS and MIROC were chosen as they displayed the respective highest and lowest percentage of variance described in the SPD and W modes. FGOALS showed a stronger tendency toward the SPD and W modes, whereas MIROC displayed a much weaker tendency, which agrees with the extensive ENSO analysis of PMIP2 models by Zheng et al. (2008). The correlation maps are given in Fig. 14. The FGOALS model has negative correlations between Eastern and Equatorial Pacific SST and the SAM and positive correlations in the South Pacific (Fig. 14a). MIROC however, has a much more zonal mid-latitude setup with the SST correlation (Fig. 14d). The real dominance of ENSO in FGOALS becomes apparent in the SPD/SST correlation field in Fig. 14b. The correlation coefficients are generally -0.5 or lower throughout the whole of the Tropical Pacific with strong positive correlations to the north and south. MIROC displays a similar pattern to FGOALS (see Fig. 14e) but the correlation coefficients are much weaker and are generally less than 0.2 in absolute magnitude. Finally the $\mathrm{W}$ mode still exhibits an ENSO component in FGOALS (Fig. 14c) but the correlation coefficients are generally within \pm 0.2 , which suggests a very weak relation. However, the work by Renwick (1998) suggests that the atmospheric response to ENSO of this mode (W) has opposing signs from September-February and March-August resulting in a "cancellation of the ENSO signal over the year", which may be occurring in FGOALS. The ENSO signal from MIROC in W is almost non-existent showing a weak ENSO in this model (Fig. 14f) as also noted in Zheng et al. (2008).

\subsection{Variability in PMIP2 models: Mid-Holocene run}

The previous section identified how the models represent the three leading EOFs in comparison to NCEP data, this section looks at how the modes may have changed during the MidHolocene. Previous work by Zheng et al. (2008) and Chiang et al. (2009) (and references therein) have both shown a reduced ENSO variance in the Mid-Holocene, which may therefore influence the modes of variability in each model and particularly the SPD and $\mathrm{W}$ modes.

As seen in the control phase, all of the models display a high spatial correlation between the present day SAM (from
NCEP data) and the Mid-Holocene SAM (see Table 2) with FGOALS and HadCM3_UB displaying the largest correlations between all three modes (SAM, SPD and W). The remaining models (CCSM3, ECHAM5 and MIROC) still have the SAM dominating the SH variability during the MidHolocene with only small changes in the variance described by the SPD and W modes relative to the control run.

The variance described by each of the modes of variability changes very little for the Mid-Holocene compared to the control run for each model, see Table 3. CCSM3, FGOALS and HadCM3_UB all indicate a slight reduction in the prevalence of the SAM whereas ECHAM5 and MIROC have a slight increase. There was also little change in the remaining two modes (SPD and W) for the Mid-Holocene compared to the control run for each model (see Table 3).

Correlations between the EOF time series and global SST anomalies were also undertaken for FGOALS and MIROC for their respective Mid-Holocene runs. The relationships to SST were very similar to those seen in the control phase and are not shown. The overall suggestion from this section is that the leading modes of variability identified in the EOF analysis (and their relation to ENSO) were very similar in the Mid-Holocene to present day despite a reduction in ENSO variability given in Zheng et al. (2008) and Chiang et al. (2009).

\section{Conclusions and discussion}

This study has identified how the PMIP2 models represent the SAO and addressed how the SAO may have been different during the Mid-Holocene. The PMIP2 models are generally capable of representing the maximum in the zonal mean $500 \mathrm{hPa}$ temperature and SLP differences between $50^{\circ} \mathrm{S}$ $65^{\circ} \mathrm{S}$ during austral autumn but give a poor representation of the maximum in austral spring. Despite these discrepancies only one of the PMIP2 models used did not show any features of the SAO and was discarded from the analysis.

The main differences between the Mid-Holocene and preindustrial model runs from PMIP2 was a weakening in the $500 \mathrm{hPa}$ temperature and SLP differences during MAM in all models and a strengthening in all but one model (MIROC) during SON. The changes in $500 \mathrm{hPa}$ temperatures agree with the changes in the SH SSTs for the Mid-Holocene, which are responding to the changes in insolation. The discrepancy in the MIROC model can also be attributed to its own seasonal SST response in the SH. As the SAO is a coupled ocean-atmosphere process, it is unsurprising that the insolation driven changes in SST influence the CPT. The results in this study therefore suggest that during the Mid-Holocene the CPT was stronger and more contracted in SON than at present but weaker and more expanded in MAM. However, the poor representation of the SAO features during SON and the role of static stability in cyclone formation during SON leads to strong uncertainty in the differences between MidHolocene climate and present day during spring. 
The analysis of temperature and precipitation on a more regional scale also acts to highlight the uncertainty in representing the Mid-Holocene climate. The models showed a systematic cooling response throughout the New Zealand region in MAM, which is likely to be associated with reduced insolation whereas a general warming during SON (possibly associated with increased insolation) was observed. However, the SON warming was not as spatially coherent between the models as in MAM and wave features observed in the SLP anomalies (for the Mid-Holocene relative to the control runs) had the potential to impact on the surface air temperature. The ensemble mean suggested a wetter New Zealand in MAM and drier conditions in SON, but the variation between models is high, which was also associated with the positioning of SLP anomalies.

As for other modes of variability (derived from the EOF analysis), all of the models showed a high spatial correlation with the SAM although all models, except for FGOALS, over-emphasised the importance of the SAM. FGOALS displayed the highest spatial correlations (for the three leading EOFs) with NCEP data but had a much stronger forcing from ENSO than the other models. Despite other studies indicating that the variability of ENSO was weaker during the MidHolocene, this did not impact very much on the occurrence of SPD and W events in the SH for all models analysed. The suggestion from this study is that the leading modes of atmospheric variability generally changed little whereas seasonal climate changed in response to the changes in Earth's orbital parameters.

This study has demonstrated that GCMs struggle to capture aspects of the SAO while showing a strong tendency toward the SAM. The results also indicate that the representation of past NZ climate is very dependent on the model used. Our future work will incorporate the use of a Regional Climate Model (RCM) centred on New Zealand to represent the climate of the Mid-Holocene (at higher resolution) and then compare it to available proxy data. This study has identified some of the large scale atmospheric circulations that may bias our future RCM experiments.

Acknowledgements. This work was funded by the New Zealand Foundation for Research Science and Technology (FRST) contracts UOAX0714 and CO1X0707. We acknowledge the international modeling groups for providing their data for analysis, the Laboratoire des Sciences du Climat et de l'Environnement (LSCE) for collecting and archiving the model data. The PMIP2/MOTIF Data Archive is supported by CEA, CNRS, the EU project MOTIF (EVK2-CT-2002-00153) and the Programme National d'Etude de la Dynamique du Climat (PNEDC). The analyses were performed using version 04-02-2009 of the database. More information is available on http://pmip2.lsce.ipsl.fr/ and http://motif.lsce.ipsl.fr/. Thanks also to Sam Dean at NIWA for providing extremely useful input in reviewing a draft version of this paper.

Edited by: V. Rath

\section{References}

Bracegirdle, T. J., Connolley, W. M., and Turner, J.: Antarctic climate change over the twenty first century, J. Geophys. Res., 113, D03103, doi:10.1029/2007JD008933, 2008.

Braconnot, P., Otto-Bliesner, B., Harrison, S., Joussaume, S., Peterchmitt, J.-Y., Abe-Ouchi, A., Crucifix, M., Driesschaert, E., Fichefet, Th., Hewitt, C. D., Kageyama, M., Kitoh, A., Laîné, A., Loutre, M.-F., Marti, O., Merkel, U., Ramstein, G., Valdes, P., Weber, S. L., Yu, Y., and Zhao, Y.: Results of PMIP2 coupled simulations of the Mid-Holocene and Last Glacial Maximum Part 1: experiments and large-scale features, Clim. Past, 3, 261277, doi:10.5194/cp-3-261-2007, 2007.

Chiang, J. C. H., Fang, Y., and Chang, P.: Pacific climate change and ENSO activity in the Mid-Holocene, J. Climate, 22, 923939, 2009.

Drost, F., Renwick, J., Bhaskaran, B., Oliver, H., and McGregor, J.: Variability of the atmospheric circulation in the Southern Hemisphere during the last glacial maximum, J. Geophys. Res., 112, D10101, doi:10.1029/2005JD006970, 2007.

Fogt, R. L., Perlwitz, J., Monaghan, A. J., Bromwich, D. H., Jones, J. M., and Marshall, G. J.: Historical SAM variability. Part II: Twentieth-century variability and trends from reconstructions, observations and the IPCC AR4 models, J. Climate, 22, 5346$5365,2009$.

Hall, N. M. J. and Valdes, P. J.: A GCM simulation of the climate 6000 years ago, J. Climate, 10, 3-17, 1997.

Hollis, C. J., Handley, L., Crouch, E. M., Morgans, H. E. G., Baker, J. A., Creech, J., Collins, K. S., Gibbs, S. J., Huber, M., Schouten, S., Zachos, J. C., and Pancost, R. D.: Tropical sea temperatures in the high-latitude South Pacific during the Eocene, Geology, 37, 99-102. 2009

Huber, M.: A hotter greenhouse?, Science, 321, 353-354, 2008.

Huber, M.: Snakes tell a torrid tale, Nature, 457, 669-671, 2009.

Jansen, E., Overpeck, J., Briffa, K. R., Duplessy, J.-C., Joos, F., Masson-Delmotte, V., Olago, D., Otto-Bliesner, B., Peltier, W. R., Rahmstorf, S., Ramesh, R., Raynaud, D., Rind, D., Solomina, O., Villalba, R., and Zhang, D.: Paleo-climate, in: Climate Change 2007: The Physical Science Basis. Contribution of Working Group I to the Fourth Assessment Report of the Intergovernmental Panel on Climate Change edited by: Solomon, S., Qin, D., Manning, M., Chen, Z., Marquis, M., Averyt, K. B., Tignor, M., and Miller, H. L., Cambridge University Press, Cambridge, UK and New York, NY, USA, 2007.

Jones, J. M., Fogt, R. L., Widmann, M., Marshall, G. J., Jones, P. D., and Visbeck, M.: Historical SAM variability. Part I: Century length seasonal reconstructions, J. Climate, 22, 5319-5345, 2009.

Joussaume, S. and Taylor K. E.: The Paleoclimate Modeling Intercomparison Project: Proceedings of the third PMIP workshop, in: WCRP-111, WMO/TD-1007, edited by: Braconnot, P., Canada, 4-8 October 1999, 25-42, 2000.

Kalnay, E., Kanamitsu, M., Kistler, R., Collins, W., Deaven, D., Gandin, L., Iredell, M., Saha, S., White, G., Woolen, J., Zhu, Y., Chelliah, M., Ebisuzaki, W., Higgins, W., Janowiak, J., Mo, K. C., Ropelewski, C., Wang, J., Leetmaa, A., Reynolds, R., Jenne, R., and Joseph, D.: The NCEP/NCAR 40-year reanalysis project, B. Am. Meteorol. Soc., 77, 437-471, 1996.

Karoly, D. J.: The role of transient eddies in low-frequency zonal variations of the Southern Hemisphere circulation, Tellus, 42A, 
41-50, 1990.

Kidson, J. W.: Principal modes of Southern Hemisphere lowfrequency variability obtained from NCEP-NCAR reanalyses, J. Climate, 12, 2808-2830, 1999.

Kidson, J. W.: An analysis of New Zealand synoptic types and their use in defining weather regimes, Int. J. Climatol., 20, 299-316, 2000.

Kidston, J., Renwick, J. A., and McGregor, J.: Hemispheric-scale seasonality in the Southern Annular Mode and impacts on the climate of New Zealand, J. Climate, 22, 4759-4770. 2009.

Kiladis, G. N. and Mo, K. C.: Interannual and intraseasonal variability in the Southern Hemisphere, in: Meteorology of the Southern Hemisphere, edited by: Karoly, D. J. and Vincent, D. G., 307-336, 1998.

Laine, A., Kageyama, M., Salas-Melia, D., Voldoire, A., Riviere, G., Ramstein, G., Planton, S., Tyteca, S., and Peterschmitt, J. Y.: Northern Hemisphere storm tracks during the last glacial maximum in the PMIP2 ocean-atmosphere coupled models: energetic study, seasonal cycle, precipitation, Clim. Dynam., 32, 593-614, 2009.

Marzin, C. and Braconnot, P.: Variations of Indian and African monsoons induced by insolation changes at 6 and $9.5 \mathrm{kyr} \mathrm{BP}$, Clim. Dynam., 33, 215-231, 2009.

Meehl, G. A.: A reexamination of the mechanism of the semiannual oscillation in the Southern Hemisphere, J. Climate, 4, 911-926, 1991.

Meehl, G. A., Hurrell, J. W., and van Loon, H.: A modulation of the mechanism of the semiannual oscillation in the Southern Hemisphere, Tellus, 50A, 442-450, 1998.

Miller, R. L., Schmidt, G. A., and Shindell, D. T.: Forced annular variations in the 20th century Intergovernmental Panel on Climate Change Fourth Assessment Report models, J. Geophys. Res., 111, D18101, doi:10.1029/2005JD006323, 2006.

Mo, K. C.: Relationships between low-frequency variability in the Southern Hemisphere and sea surface temperature anomalies, J. Climate, 13, 3599-3610, 2000.

Perlwitz, J., Pawson, S., Fogt, R. L., Nielsen, J. E., and Neff, W. D.: Impact of stratospheric ozone hole recovery on Antarctic climate, Geophys. Res. Lett., 35, L08714, doi:10.1029/2008GL033317, 2008.

Randall, D. A., Wood, R. A., Bony, S., Colman, R., Fichefet, T., Fyfe, J., Kattsov, V., Pitman, A., Shukla, J., Srinivasan, J., Stouffer, R. J., Sumi, A., and Taylor, K. E.: Climate Models and Their Evaluation, in: Climate Change 2007: The Physical Science Basis. Contribution of Working Group I to the Fourth Assessment Report of the Intergovernmental Panel on Climate Change, edited by: Solomon, S., Qin, D., Manning, M., Chen, Z., Marquis, M., Averyt, K. B., Tignor, M., and Miller, H. L.: Cambridge University Press, Cambridge, UK and New York, NY, USA, 2007.

Raphael, M. N. and Holland, M. M.: Twentieth century simulation of the Southern Hemisphere climate in coupled models. Part 1: large scale circulation variability, Clim. Dynam., 26, 217-228, 2006.

Rayner, N. A., Brohan, P., Parker, D. E., Folland, C. K., Kennedy, J. J., Vanicek, M., Ansell, T. J., and Tett, S. F. B.: Improved analyses of changes and uncertainties in sea surface temperature measured in situ since the Mid-Nineteenth Century: The HadSST2 dataset, J. Climate, 19, 446-469, 2006.
Renwick, J. A.: ENSO-Related variability in the Frequency of South Pacific Blocking, Mon. Weather Rev., 126, 3117-3123, 1998

Renwick, J. A.: Southern Hemisphere circulation and relations with sea ice and sea surface temperature, J. Climate, 15, 3058-3068, 2002.

Renwick, J. A. and Revell, M. J.: Blocking over the South Pacific and Rossby wave propagation, Mon. Weather Rev., 127, 22332247, 1999.

Rojas, M., Moreno, P., Kageyama, M., Crucifix, M., Hewitt, C., Abe-Ouchi, A., Ohgaito, R., Brady, E. C., and Hope, P.: The Southern Westerlies during the last glacial maximum in PMIP2 simulations, Clim. Dynam., 32, 525-548, 2009.

Salinger, M. J. and Mullan, A. B.: New Zealand climate: Temperature and precipitation variations and their links with atmospheric circulation 1930-1994, Int. J. Climatol., 19, 1049-1071, 1999.

Simmonds, I.: Modes of atmospheric variability over the Southern Ocean, J. Geophys. Res., 108, doi:10.1029/2000JC000542, 2003.

Simmonds, I. and Jones, D. A.: The mean structure and temporal variability of the semiannual oscillation in the southern extratropics, Int. J. Climatol., 18, 473-504, 1998.

Simmonds, I. and Lim, E.-P.: Biases in the calculation of Southern Hemisphere mean baroclinic eddy growth rate, Geophys. Res. Lett., 36, L01707, doi:10.1029/2008GL036320, 2009.

Simmonds, I. and Walland, D. J: Decadal and centennial variability of the southern semiannual oscillation simulated in the GFDL coupled GCM, Clim. Dynam., 14, 45-53, 1998.

Taschetto, A., Wainer, I., and Raphael, M.: Interannual variability associated with Semiannual Oscillation in southern high latitudes, J. Geophys. Res., 112, D02106, doi:10.1029/2006JD007648, 2007.

Thompson, D. W. J. and Wallace, J. M.: Annular modes in the extratropical circulation. Part I: Month-to-month variability, J. Climate, 13, 1000-1016, 2000.

van den Broeke, M.: The semi-annual oscillation and Antarctic climate. Part 3: The role of near-surface wind speed and cloudiness, Int. J. Climat., 20, 117-130, 2000a.

van den Broeke, M.: The semi-annual oscillation and Antarctic climate. Part 5: impact on the annual temperature cycle as derived from NCEP/NCAR re-analysis, Clim. Dynam., 16, 369377, 2000b.

van Loon, H.: The half yearly oscillations in middle and high southern latitudes and the coreless winter, J. Atmos. Sci., 24, 472-486, 1967.

van Loon, H., Kidson, J. W., and Mullan, A. B.: Decadal variation of the annual cycle in the Australian dataset, J. Climate, 6, 1227$1231,1993$.

Walland, D. and Simmonds, I.: Baroclinicity, meridional temperature gradients, and the southern semiannual oscillation, J. Climate, 12, 3376-3382, 1999.

Zheng, W., Braconnot, P., Guilyardi, E., Merkel, U., and Yu, Y. ENSO at $6 \mathrm{ka}$ and $21 \mathrm{ka}$ from ocean-atmosphere coupled model simulations, Clim. Dynam., 30, 745-762, 2008. 